\title{
The effect of a numerical domino game on numerical magnitude processing in children with mild intellectual disabilities
}

\author{
Carmen Brankaer, Pol Ghesquière, and Bert De Smedt \\ Parenting and Special Education Research Unit \\ Faculty of Psychology and Educational Sciences \\ KU Leuven, Belgium
}

Correspondence concerning this article should be addressed to Carmen Brankaer, Parenting and Special Education Research Unit, Leopold Vanderkelenstraat 32, box 3765, B-3000 Leuven, Belgium. E-mail: Carmen.Brankaer@ppw.kuleuven.be. Tel. +32 16326182 or to Bert De Smedt, Parenting and Special Education Research Unit, Leopold Vanderkelenstraat 32, box 3765, B-3000 Leuven, Belgium. E-mail: Bert.DeSmedt@ppw.kuleuven.be. Tel. +32 163257 05. Fax. +3216325933 


\begin{abstract}
Children with mild intellectual disabilities (MID) appear to have particular problems in understanding the numerical meaning of Arabic digits. Therefore, we developed and evaluated a numerical domino game that specifically targeted the association between these digits and the numerical magnitudes they represent. Participants were 30 children with MID ( $M=8.36$ years), randomly assigned to either the numerical domino game or to a control color domino game. Findings revealed that both groups of children improved on a non-symbolic comparison and arithmetic task. Most importantly, only children who played the numerical domino game became significantly faster from pretest to posttest on a symbolic comparison task These findings suggest that numerical magnitude processing can be successfully trained in children with MID.
\end{abstract}




\section{Introduction}

Children with mild intellectual disabilities (MID) often show difficulties in the development of mathematical skills (Geary, 1994; Kroesbergen \& Van Luit, 2005). Because mathematical abilities are crucial in modern Western societies (Chiswick, Lee, \& Miller, 2003), it is important to gain insight into the cognitive processes underlying these difficulties. It has been proposed that number sense or the ability to understand and represent numerical magnitudes plays an important role in mathematical difficulties (e.g., Butterworth, Varma, \& Laurillard, 2011). Indeed, Brankaer, Ghesquière, and De Smedt (2011) found that children with MID had impairments in numerical magnitude processing. Several studies demonstrated that game-based interventions have a positive effect on numerical magnitude representations in typically developing children (e.g., Whyte \& Bull, 2008), children from low-income backgrounds (e.g., Ramani \& Siegler, 2008) and children with mathematical difficulties (e.g., Kucian et al., 2011), but none of these studies focused on children with MID. Against this background, the present study aimed to develop and evaluate an intervention to improve the numerical knowledge of children with MID.

According to most classification systems, an intellectual disability is characterized by significant limitations in intellectual functioning and adaptive behaviour skills (AAIDD, see Schalock et al., 2010; APA, 2000; WHO, 1993). Based on children’s IQ-scores, various levels of severity of intellectual disability can be distinguished: mild (IQ level 50-55 to approximately 70), moderate (IQ level 35-40 to 50-55), severe (IQ level 20-25 to 35-40) and profound (IQ level below 20-25) (APA, 2000). Baroody (1999) reported a series of case studies of children with mild to severe intellectual disabilities and observed that these children often experience mathematical difficulties. Additionally, Hoard, Geary, and Hamson (1999) found that children with a below-average intelligence displayed deficits when they had to name and write Arabic digits. These children also had problems with detecting 
counting errors and with simple addition. The latter was confirmed by Janssen, De Boeck, Viaene, and Vallaeys (1999), who showed that children with MID were less accurate when solving addition problems than typically developing children. Because mathematical abilities are crucial in modern Western societies, (e.g., getting change in a shop, reading timetables to catch a bus), it is important to gain insight into the cognitive processes underlying these difficulties and to use this knowledge as a scientifically sound basis for appropriate remedial teaching and mathematics education.

Research on individual differences in mathematics achievement has attributed a crucial role to the ability to understand and represent numerical magnitudes in the development of mathematics skill (e.g., Butterworth et al., 2011 and De Smedt, Noël, Gilmore, \& Ansari, 2013, for reviews). This ability seems to be related to and even predictive of mathematics achievement in typically developing children (De Smedt et al., 2013; De Smedt, Verschaffel, \& Ghesquière, 2009; Halberda, Mazzocco, \& Feigenson, 2008; Holloway \& Ansari, 2009; Reigosa-Crespo et al., 2012). Children with mathematical difficulties are known to have problems with the understanding and processing of numerical magnitudes (De Smedt \& Gilmore, 2011; Landerl, Bevan, Butterworth, 2004; Mussolin et al., 2010) and show abnormalities in brain areas that are involved in numerical magnitude processing (see Butterworth et al., 2011). More specifically, several studies have demonstrated that especially the speed of children's symbolic magnitude processing is related to their mathematics achievement (De Smedt et al., 2009; Holloway \& Ansari, 2009).

Turning to children with intellectual disabilities, Hoard et al. (1999) revealed that children with below-average intelligence $\left(M_{I Q}=78\right)$ were less accurate in identifying the larger of two Arabic digits, a classic task to investigate numerical magnitude processing in children (Sekuler \& Mierkiewicz, 1977), compared with their typically developing peers. Recently, Brankaer et al. (2011) investigated numerical magnitude processing in children with MID 
$\left(M_{I Q}=62\right)$ more systematically, by comparing the performance of these children on symbolic (digits) and non-symbolic (dot patterns) numerical magnitude comparison tasks with the performance of two control groups of typically developing children, one group matched on chronological age and one group matched on arithmetic achievement level. Findings revealed that children with MID performed more poorly than their chronological age-matched peers on both the symbolic and non-symbolic comparison tasks, which indicates that children with MID have problems in the development of numerical magnitude representations.

Various studies in children with a normal intelligence have shown that interventions that focus on numerical magnitude processing improve children's numerical knowledge (e.g., Ramani \& Siegler, 2011). Some of these interventions were intensive and addressed several aspects of numerical magnitude processing and mathematical knowledge, such as 'Number Worlds' (Griffin, 2004). This program mostly consisted of educational games at classroom level and was based on five instructional principles: (a) build further on the current knowledge of the child, (b) follow the natural course of development, (c) focus both on conceptual understanding and on calculations, (d) make maximum use of exploration, problem solving and communication and (e) expose children to all possible representations of quantities, such as objects, dot arrays and positions on a number line. A longitudinal study in which kindergarteners from low-income backgrounds were followed from preschool to the first years of formal schooling showed that the children who practiced with 'Number Worlds' improved significantly in conceptual knowledge of number and in number sense.

Recently, Jordan, Glutting, Dyson, Hassinger-Das, and Irwin (2012) developed another intervention program that also focused on numerical magnitude processing. During this intervention, kindergartners from low-income communities had to follow 24 30-minute lessons, in which activities such as number recognition, number sequencing, problem solving and linear board game playing, were implemented. Two control groups were included: one 
group of children who received vocabulary instruction and one group of children who received business as usual. Findings revealed that children who received the numerical intervention outperformed the control children on several measures of number competencies and general math achievement at the posttest. Follow-up data showed that many of these intervention effects held eight weeks after the intervention.

Other intervention studies were less comprehensive and only focused on specific aspects of numerical magnitude processing, often presented through numerical board games. For example, Siegler and Ramani (2008) showed that playing a linearly organized numerical board game for four 15-minute sessions had a positive effect on the numerical knowledge of kindergarteners from low-income backgrounds. In this study, children in the experimental condition played a board game that consisted of 10 horizontally arranged squares that had the numbers 1-10 listed consecutively from left to right. Children had to spin a spinner and then move their token the number of spaces indicated on the spinner (one or two), while saying the numbers on the spaces through which they moved. In the control condition, children had to do the same, but now with colors instead of numbers. The numerical board game improved low-income children's knowledge of numerical magnitudes, as measured by a number line task, to the point where they reached the same performance level as middle-income children who did not play the game. The color board game did not show this effect. Several studies have found similar effects in larger groups of pre-schoolers and by using diverse numerical tasks, such as counting, numeral identification, numerical magnitude comparison, number line estimation and arithmetic problem solving (Ramani \& Siegler, 2008, 2011; Siegler \& Ramani, 2009; Whyte \& Bull, 2008).

These board games have also been implemented in a computer-based format. For example, 'The Number Race' game (Wilson et al., 2006a) aims to train children to make numerical magnitude comparisons and attempts to strengthen the connections between 
symbolic and non-symbolic magnitude representations by simultaneously presenting different formats of magnitudes (Arabic digits, dot-arrays and number words). The game is adaptive and also includes training on the conceptualization and automatization of addition and subtraction facts in later stages of the game. Studies in children with mathematical difficulties (Räsänen, Salminen, Wilson, Aunio, \& Dehaene, 2009; Wilson, Revkin, Cohen, Cohen, \& Dehaene, 2006b) or children from low-income backgrounds (Wilson, Dehaene, Dubois, \& Fayol, 2009) have shown that The Number Race has positive effects, particularly it improves children’s symbolic comparison performance.

More recently, Kucian et al. (2011) developed the 'Rescue Calcularis' game, in which children had to position Arabic digits, addition and subtraction problems or dot arrays on a number line from 0 to 100 . Twenty-five training sessions of 15 minutes led to an improved spatial representation of numbers and better arithmetical skills in children with mathematical difficulties.

The above mentioned studies indicate that specific short interventions can improve children's numerical magnitude representations and, additionally, can have a positive effect on their mathematical skills. However, none of these studies focused on children with MID, although these children are known to have difficulties in processing numerical magnitudes (Brankaer et al., 2011). Therefore, the goal of the present study was to develop and evaluate an intervention for children with MID. We presented the intervention in a game-like format because previous studies in children with mathematical difficulties (Wilson et al., 2006b; Kucian et al., 2011) and from low-income backgrounds (Ramani \& Siegler, 2008, 2011; Siegler \& Ramani, 2008, 2009) have shown that simple short games are particularly effective in fostering children's numerical representations. The intervention comprised eight 15-minutes sessions, which was somewhat more than in previous interventions in kindergarteners from low-income backgrounds (Ramani \& Siegler, 2008; Siegler \& Ramani, 
2009). This was done because children with MID are expected to be slower learners than children with an average intelligence.

Brankaer et al. (2011) showed that the difficulties of children with MID were more prominent on the symbolic than on the non-symbolic comparison task, suggesting that these children have difficulties in understanding the numerical meaning of Arabic digits. Against this background, we developed a numerical domino game that particularly focuses on the association between these numerical symbols and the quantities they represent. The effects of this game were evaluated with a randomized pretest-posttest design with two groups of children: one group that played the numerical domino game and one control group that played a color domino game, which was comparable to the numerical version with as only difference that numerical magnitudes were replaced by colors. Before and after the intervention, we examined children's performance on a symbolic and non-symbolic magnitude comparison task as well as their performance on a general standardized test for arithmetic. We hypothesized that children who played the numerical domino game would improve more in numerical magnitude processing than children who played the control color domino game, and that their improvement would be most pronounced on the symbolic comparison task because this task specifically targets the connection between Arabic digits and the magnitudes they represent. We predicted that especially children's reaction times on this task would improve because response speed is a more sensitive measure that can reveal differences in numerical magnitude processing that may not be uncovered when looking at accuracy only (see Berch, 2005, for a discussion). In view of the established association between symbolic magnitude processing and mathematics achievement (De Smedt et al., 2009; Holloway \& Ansari, 2009), we hypothesized that the intervention would also have a positive effect on children's general arithmetical abilities. 


\section{Method}

\section{Participants}

Participants were recruited from three special education schools for children with MID. To get enrolled in this type of school, children need an attest that reports on their intelligence and provides them with a clinical diagnosis of MID. The following three standardized intelligence tests were administered as measures of intellectual ability: (1) the Dutch version of the Wechsler Preschool and Primary Scale of Intelligence - Revised (WPPSI- ${ }^{\mathrm{NL}}$; Vander Steene \& Bos, 1997), (2) the Dutch version of the Wechsler Intelligence Scale for Children Third Edition (WISC-III ${ }^{\mathrm{NL}}$; Kort et al., 2005), or (3) Snijders-Oomen Nonverbal Intelligence Test Revised (SON-R 2.5-7; Tellegen et al., 1998). Against the background of DSM-IV-TR criteria for defining MID (APA, 2000), only children with an IQ between 55 and 75 were included. The final sample consisted of 30 children with MID (16 boys, $M_{\text {age }}=8.36$ years, $S D=0.83)$. Parental consent was obtained for all children.

Within each school, participants were randomly assigned to either the numerical domino game or to the color domino game. The numerical domino game condition consisted of 15 children ( 8 boys, $M_{\text {age }}=8.23$ years, $S D_{\text {age }}=0.98$, Range age $=6.96-9.64, M_{\mathrm{IQ}}=67.20$, $S D_{\mathrm{IQ}}=5.38$, Range $\left._{\mathrm{IQ}}=57-75\right)$, and 15 children were assigned to the color domino game condition (8 boys, $M_{\text {age }}=8.48$ years, $S D_{\text {age }}=0.65$, Range $_{\text {age }}=7.34-9.48, M_{\mathrm{IQ}}=67.00$, $S D_{\mathrm{IQ}}=5.43$, Range $\left.\mathrm{IQ}_{\mathrm{IQ}}=57-73\right)$. Groups did not differ in chronological age $(t(28)=0.82$, $\left.p=.42, \eta_{p}^{2}=.02\right)$ or in intellectual ability $\left(t(28)=0.10, p=.92, \eta_{p}^{2}<.01\right)$ and were perfectly matched on sex and educational environment.

\section{Materials and Procedure}

Ethical approval for the study was given by the University ethics committee. The intervention consisted of eight 15-minute sessions, two sessions a week, similar to previous interventions (Ramani \& Siegler, 2011; Siegler \& Ramani, 2009). Each child met one-on-one 
with a trained experimenter and both competed with each other in a domino game. In each session, two different versions of the game were played for about 7 minutes to keep children's attention and motivation high. All children met with the same experimenter in all intervention sessions. All sessions took place in a quiet room at the school of the children.

Numerical domino game. The domino tiles were $6 \times 3 \mathrm{~cm}$. Each tile consisted of two equal $3 \times 3 \mathrm{~cm}$ squares, divided by a vertical line. On one side of the tile an Arabic digit was printed, while the other side showed a dot array or collection of objects (car, star, butterfly, ball or a combination). The child and experimenter started each with 5 or 7 tiles, depending on the total number of tiles that were used in the game: 25 tiles were used for the quantities 1 to 5 and 6 to 10 (start with 5 tiles), while 50 tiles were used for the quantities from 1 to 10 (start with 7 tiles). Then, both players took turns placing a tile on the table. A tile could be played when the quantity shown on that tile matched the quantity of the tile on the table, i.e. when the Arabic digit matched the dot/object array and vice versa (Figure 1). The first player who played all his tiles, or the player with the fewest tiles left at the end of the game, i.e. after 7 minutes, won the game. In the first three intervention sessions, quantities from 1 to 5 were presented. In session 4 to 6 , tiles with quantities from 6 to 10 were used. In the last two sessions (session 7 - 8), children had to play with quantities in the 1 to 10 range. In session 1 , 4, 7 and 8, only tiles with digits and dot arrays were used. In the remaining sessions, a combination of tiles with digits, dot arrays and object arrays was presented. Furthermore, in session 3, 6 and 8, a time-limit of 10 seconds to play a tile was introduced, encouraging the children to answer as quickly as possible (see Appendix for a more detailed overview of the course of the sessions).

Color domino game. This game was comparable to the numerical domino game, with the only difference that colors replaced Arabic digits and colored shapes/cartoon-figures were used instead of dot/object arrays (Figure 1). The eight intervention sessions followed exactly 
the same procedure as the numerical condition and the same playing rules were applied. Children had to match the correct color with the correct colored shape/cartoon-figure and vice versa. Detailed information about the course of the sessions is shown in the Appendix.

\section{Pre- and Posttest Measures}

Pre- and posttests were administered one week before and after the intervention. All participants were tested individually in a quiet room at their own school during regular school hours.

Computerized tasks. The computerized tasks were presented using the E-prime 2.0 software (Schneider, Eschmann, \& Zuccolotto, 2002) on a 17 inch laptop. Children were instructed to perform both accurately and quickly. Stimuli occurred in white on a black background in Arial font (size 72). Each trial started with a 250ms fixation cross in the centre of the screen. After $1000 \mathrm{~ms}$ the stimulus appeared and remained visible until a response occurred, except for the non-symbolic numerical magnitude comparison task where the stimulus disappeared after $840 \mathrm{~ms}$, in order to avoid counting. Each trial was initiated by the experimenter with a control key. Participants had to respond by pressing a key on a computer keyboard that was put in front of the laptop and was connected to it. The left response key, labeled with a blue sticker, was 'd'; the right response key, labeled with a yellow sticker, was ' $k$ '. Each task was preceded by three practice trials to familiarize the child with the key assignments. Answers and reaction times were recorded by the laptop.

Symbolic numerical comparison. A classic numerical magnitude comparison task (Sekuler \& Mierkiewicz, 1977) was administered. In this task, children had to indicate the numerically larger of two simultaneously presented Arabic digits, one displayed on the left and one displayed on the right side of the screen. Stimuli involved all combinations of the digits 1 to 9, yielding 72 trials. Children had to answer by pressing the response key on the side of the larger digit. The position of the largest digit was counterbalanced. 
Non-symbolic numerical comparison. Children had to indicate the larger of two simultaneously presented dot arrays, one displayed on the left and one displayed on the right side of the screen. Stimuli comprised the same numerosities as in the symbolic comparison task, yielding 72 trials. The stimuli were generated with the MATLAB script provided by Piazza, Izard, Pinel, Le Bihan, and Dehaene (2004) and were controlled for non-numerical parameters, i.e. individual dot size, total occupied area, and density. This was done to reduce the likelihood that children would rely on these non-numerical cues or perceptual features to make a correct decision. Similar to the symbolic comparison task, children had to select the larger numerosity by pressing the response key on the side of the larger numerosity. The position of the largest numerosity was counterbalanced.

Control task: Motor reaction time. This task was included to control for children's response speed on the keyboard. Two figures appeared on the screen, one of which was colored white. The child had to press as soon as possible on the side of this white figure. Twenty experimental trials were presented.

Paper-and-pencil test: arithmetical ability. Arithmetical ability was assessed using a standardized paper-and-pencil arithmetic achievement test, Tempo Test Arithmetic (de Vos, 1992). In this test, children had to solve basic arithmetic problems as accurately and quickly as possible (e.g., $7+2=$ ). For each operation, 40 problems of increasing difficulty were presented and children were required to solve as many problems as possible within a oneminute period. In this study, we only presented the addition problems, as our participants did not yet receive instruction in subtraction, multiplication and division. The score on this test was the number of correctly solved problems within one minute.

\section{Results}

Table 1 shows the descriptive statistics of both groups at the pre- and posttest. Mean reaction times were based on correct responses only. The effect of the intervention was 
evaluated with a repeated measures ANOVA with Session (pretest vs. posttest) as withinsubjects factor and Group (color vs. numerical) as between-subjects factor on children's accuracy and reaction time. Partial eta-squared was calculated as a measure of effect size. It is important to note that no significant group differences were observed on the pretest measures ( $p s>.15$ ), indicating that randomization was successful and that both groups started at a comparable performance level.

\section{Control task}

Accuracy on this task was very high $(\geq 97 \%)$ and at ceiling. For response speed, no main effect of group $\left(F(1,28)=0.01, p=.99, \eta_{p}^{2}<.01\right)$, main effect of session $(F(1,28)=0.52$, $\left.p=.48, \eta_{p}^{2}=.02\right)$ or interaction between group and session $\left(F(1,28)=0.10, p=.76, \eta_{p}^{2}<\right.$ .01) were found. This excludes the possibility that the intervention effects would be due to increases or group differences in general response speed.

\section{Symbolic numerical comparison}

With regard to accuracy, there was no main effect of group $(F(1,28)=0.01, p=.93$, $\left.\eta_{p}^{2}<.01\right)$ or session $\left(F(1,28)=1.06, p=.31, \eta_{p}^{2}=.04\right)$ and no group $\times$ session interaction was found, $F(1,28)=1.43, p=.24, \eta_{p}^{2}=.05$.

Turning to reaction times, there was no main effect of group $(F(1,28)=0.35, p=.56$, $\left.\eta_{p}{ }^{2}=.01\right)$ or session $\left(F(1,28)=0.01, p=.92, \eta_{p}{ }^{2}<.01\right)$ but the expected group $\times$ session interaction was significant, $F(1,28)=7.75, p=.01, \eta_{p}{ }^{2}=.22$ (Figure 2). Children who played the numerical domino game became significantly faster from pretest to posttest (paired$\left.t(14)=-2.21, p=.04, \eta_{p}^{2}=.26\right)$, while children who played the color domino game did not $\left(\right.$ paired-t(14) $\left.=1.77, p=.10, \eta_{p}^{2}=.18\right)$.

\section{Non-symbolic numerical comparison}

With respect to accuracy, no main effect of group was found, $F(1,28)=1.65, p=.21$, $\eta_{p}{ }^{2}=.06$. There was a trend for improvement in the number of correctly solved items from 
pretest to posttest, $F(1,28)=3.92, p=.06, \eta_{p}{ }^{2}=.12$, yet the group $\times$ session interaction was not significant, $F(1,28)=1.02, p=.32, \eta_{p}^{2}=.04$.

Turning to reaction time, no main effect of group was found, $F(1,28)=0.02, p=.90$, $\eta_{p}{ }^{2}<.01$. Children became significantly faster from pretest to posttest, as illustrated by a main effect of session, $F(1,28)=6.75, p=.02, \eta_{p}{ }^{2}=.19$, but no interaction between group and session was found, $F(1,28)=0.32, p=.57, \eta_{p}^{2}=.01$.

\section{Arithmetical ability: addition}

There was no main effect of group, $F(1,28)=0.76, p=.39, \eta_{p}^{2}=.06$. Children improved in the number of correctly solved addition problems from pretest to posttest $(F(1,28)=6.25$, $\left.p=.02, \eta_{p}{ }^{2}=.18\right)$, but there was no group difference in the extent of their progress, $F(1,28)=1.75, p=.20, \eta_{p}^{2}=.06$

\section{Discussion}

Understanding the cognitive processes underlying mathematical difficulties is important to design appropriate interventions. Children with MID are known to have problems with the development of mathematical abilities, and these problems may be related to the difficulties these children experience with numerical magnitude representations (Brankaer et al., 2011). Against this background, we developed an intervention that tried to foster children's numerical representations, and in particular children's connections between Arabic digits and the quantities they represent. Because previous studies in children with mathematical difficulties (Wilson et al., 2006b) and from low-income backgrounds (Ramani \& Siegler, 2008, 2011; Siegler \& Ramani, 2008, 2009) have shown that short simple games are particularly effective in fostering children's numerical representations, we developed a numerical domino game and tested the hypothesis that playing this domino game would improve children's ability to understand and represent numerical magnitudes, and in particular their ability to connect symbolic numbers with the magnitudes they represent. 
Findings revealed that children improved on the non-symbolic comparison and arithmetic task from pretest to posttest, regardless of the domino game they played. However, on the symbolic comparison task only children who played the numerical domino game became significantly faster from pretest to posttest, while children who played the color domino game did not. This fits with our expectations and indicates that the numerical domino game especially strengthens the connection between Arabic digits and their corresponding magnitudes, a particular area of difficulty for children with MID (see Brankaer et al., 2011). It is important to point out that the present findings should be treated with great caution. As illustrated in Figure 2, it is possible that regression to the mean could have influenced the present findings because both groups of children showed a difference of nearly 200ms at the pretest in response speed on symbolic numerical comparison, even though this difference was not statistically significant. Nevertheless, we would like to stress that our participants were randomly assigned to two groups: One group that played the numerical domino game and one group that played the color domino game. This random assignment should have reduced the effect of regression to the mean, because both groups should be equally affected by this effect (see Barnett, van der Pols and Dobson, 2004).

Contrary to our expectations, the improvement on addition problem solving was not larger in the numerical domino group than in the color domino group, suggesting that the observed improvement might be due to practice effects. Therefore, one might question whether the numerical domino game can lead to true far-transfer effects to arithmetic achievement. The absence of this generalization effect is similar to some earlier intervention studies on numerical magnitude processing (Räsänen et al., 2009; Wilson et al., 2009), but different from others that showed generalization effects to mathematics achievement (Jordan et al., 2012; Siegler \& Ramani, 2009). A possible explanation for this finding is that the latter studies also included arithmetic problem solving training in their intervention, whereas we 
did not. Future research should therefore investigate whether including an additional arithmetic component in the present intervention could lead to larger generalization effects. Furthermore, some studies (e.g., Jordan et al., 2012) also included subtraction problems, whereas we only focused on addition. The latter was done because our participants with MID only received instruction in addition so far. It is possible that subtraction draws more strongly on numerical magnitude processing than addition (Wilson et al., 2006b), so that intervention effects would generalize more easily to subtraction than to addition problems. It is also important to point out that Jordan et al. (2012) and Siegler and Ramani (2009) included children with normal intellectual ability. By contrast, the present study comprised children with MID, popularly known as 'slower learners'. These children with MID were enrolled in special education schools and already received some years of formal education. It is possible that they need more (intensive) training sessions in order to obtain larger generalization effects. Future studies, varying in training intensity, should investigate this possibility.

Another important difference between the present study and previous ones is that the numerical domino game did not provide any linear spatial cues, while the other studies did in the format of a board game (Jordan et al., 2012; Siegler \& Ramani, 2009) or number line (Kucian et al., 2011). Although Whyte and Bull (2008) showed that playing a nonlinear number game - in which a link between Arabic digits and their magnitudes was provided also improved children's numerical magnitude understanding, other studies have pointed to the importance of these linear spatial aspects (Ramani \& Siegler, 2011; Siegler \& Ramani, 2009). Against this background, it might be interesting for future studies to add an additional intervention group that practices with a game with linear cues to determine whether these linear cues could enlarge the intervention effects of our numerical domino game. Related to this, van Nes and Doorman (2011) highlighted the importance of spatial structures in children's mathematical development. Therefore it might be interesting for future studies to 
include an additional intervention group in which children practice with structured dot patterns on their domino tiles.

It should be noted that the sample size of our study was relatively small, which might have impacted on the results of the current investigation. However, our data show that even in the current sample, a short intervention can positively affect numerical magnitude processing skills in children with MID. Additionally, a post-hoc power analysis for the current sample size by means of the G*power program (Erdfelder, Faul, \& Buchner, 1996) demonstrated that the present study had a power of .98 to detect a medium effect $\left(\eta^{2}=.13\right)$ and a power of .76 to detect an effect of a similar size as observed in other intervention studies that used slightly different interventions (e.g., Ramani \& Siegler, 2008). This suggests that the present study had sufficient power to detect meaningful intervention effects. Still, it would be useful for future research to investigate the effects of the game in larger groups of children with MID.

The finding that the numerical domino game led to significant improvements in children's symbolic number comparison speed, is promising and it would be worthwhile for future studies to intensify the training for children with MID with more and longer sessions. This could be done by involving parents more actively in the intervention program and letting them practice with their child at home. Alternatively, one could investigate whether the same learning effects would occur if children would practice in small groups rather than with one experimenter. Ramani, Siegler, and Hitti (2012) already explored this option in children from low-income backgrounds and found that small group activities are an effective way to promote early mathematical abilities. It is even possible that children will learn more in group, as they can learn from each other while playing the game.

The numerical domino game used in the present study has several advantages that recommend it for widespread use. For example, it requires little instruction for (remedial) 
teachers and parents, because most of them are already familiar with the principles of a classic domino game. The game format is motivating and most children really enjoy playing these types of games (see Ramani \& Siegler, 2008). The difficulty of the game can also be easily adapted to children's individual performance level, which has positive effects on the child's motivation and attention (see Wilson et al., 2006a for a similar rationale). 


\section{References}

American Psychological Association. (2000). Diagnostic and statistical manual of mental disorders text revision $\left(4^{\text {th }}\right.$ ed.). Washington, DC: American Psychological Association.

Barnett, A. G., van der Pols, J. C., \& Dobson, A. J. (2005). Regression to the mean: what is it and how to deal with it. International Journal of Epidemiology, 34, 215-220.

Baroody, A. J. (1999). The development of basic counting, number, and arithmetic knowledge among children classified as mentally handicapped. In L. M. Glidden (Ed.), International review of research in mental retardation Vol. 22. (pp. 51-103). San Diego, CA: Academic Press.

Berch, D. B. (2005). Making sense of number sense: Implications for children with mathematical disabilities. Journal of Learning Disabilities, 38, 333-339. doi: $10.1177 / 00222194050380040901$

Brankaer, C., Ghesquière, P., \& De Smedt, B. (2011). Numerical magnitude processing in children with mild intellectual disabilities. Research in Developmental Disabilities, 32, 2853-2859. doi:10.1016/j.ridd.2011.05.020 pp.2853-9

Bugden, S., \& Ansari, D. (2011). Individual differences in children's mathematical competence are related to the intentional but not automatic processing of Arabic numerals. Cognition, 118, 35-47. doi: 10.1016/j.cognition.2010.09.005

Butterworth, B., Varma, S., \& Laurillard, D. (2011). Dyscalculia: From brain to education. Science, 332, 1049-1053. doi: 10.1126/science.1201536

Chiswick, B. R., Lee, Y. L., \& Miller, P. W. (2003). Schooling, literacy, numeracy and labour market success. The Economic Record, 79, 165-181. doi: 10.1111/14754932.t01-1-00096

De Smedt, B., \& Gilmore, C. K. (2011). Defective number module or impaired access? 
Numerical magnitude processing in first graders with mathematical difficulties. Journal of Experimental Child Psychology, 108, 278-292. doi: 10.1016/j.jecp.2010.09.003

De Smedt, B., Noël, M. P., Gilmore, C., \& Ansari, D. (2013). The relationship between symbolic and non-symbolic numerical magnitude processing and the typical and atypical development of mathematics: evidence from brain and behavior. Trends in Neuroscience and Education, 2, 48-55.

De Smedt, B., Verschaffel, L., \& Ghesquière, P. (2009). The predictive value of numerical magnitude comparison for individual differences in mathematics achievement. Journal of Experimental Child Psychology, 103, 469-479. doi: 10.1016/j.jecp.2009.01.010

De Vos, T. (1992). Tempo-Test-Rekenen. Handleiding. [Tempo Test Arithmetic. Manual]. Nijmegen: Berkhout.

Erdfelder, E., Faul, F., \& Buchner, A. (1996). GPOWER: A general power analysis program. Behavior Research Methods, Instruments, \& Computers, 28, 1-11.

Geary, D. C. (1994). Children's mathematical development. Research and practical applications. Washington, DC: American psychological Association.

Griffin, S. (2004). Building number sense with number worlds: a mathematics program for young children. Early Childhood Research Quarterly, 19, 173-180. doi: 10.1016/j.ecresq.2004.01.012

Halberda, J., Mazzocco, M. M. M., \& Feigenson, L. (2008). Individual differences in nonverbal number acuity correlate with maths achievement. Nature, 455, 665-668. doi:10.1038/nature07246

Hoard, M. K., Geary, D. C., \& Hamson, C. O. (1999). Numerical and arithmetical cognition: performance of low- and average-IQ children. Mathematical Cognition, 5, 65-94. doi: 


\section{$10.1080 / 135467999387324$}

Holloway, I. D., \& Ansari, D. (2009). Mapping numerical magnitudes onto symbols: The numerical distance effect and individual differences in children's mathematics achievement. Journal of Experimental Child Psychology, 103, 17-29. doi:10.1016/j.jecp.2008.04.001

Janssen, R., De Boeck, P., Viaene, M., Vallaeys, L. (1999). Simple mental addition in children with and without mild mental retardation. Journal of Experimental Child Psychology, 74, 261-281. doi: 10.1006/jecp.1999.2527

Jordan, N. C., Glutting, J., Dyson, N., Hassinger-Das, B., \& Irwin, C. (2012). Building kindergartners’ number sense: a randomized controlled study. Journal of Educational Psychology, 104, 647-660. doi: 10.1037/a0029018

Kroesbergen, E. H., \& Van Luit, J. E. H. (2005). Constructivist mathematics education for students with mild mental retardation. European Journal of Special Needs Education, 20, 107-116. doi: 10.1080/0885625042000319115

Kucian, K., Grond, U., Rotzer, S., Henzi, B., Schönmann, C., Plangger, F., Gälli, M., Martin, E., \& von Aster, M. (2011). Mental number line training in children with developmental dyscalculia. Neuroimage, 57, 782-795. doi: 10.1016/j.neuroimage.2011.01.070

Landerl, K., Bevan, A., \& Butterworth, B. (2004). Developmental dyscalculia and basic numerical capacities: A study of 8-9-year-old students. Cognition, 93, 99-125. doi: 10.1016/j.cognition.2003.11.004

Mussolin, C., De Volder, A., Grandin, C., Schlögel, X., Nassogne, M. C., \& Noël, M. P. (2010). Neural correlates of symbolic number comparison in developmental dyscalculia. Journal of Cognitive Neuroscience, 22:5, 860-874. doi: 10.1162/jocn.2009.21237 
Kort, W., Schittekatte, M., Bosmans, M., Compaan, E. L., Dekker, P. H., Vermeir, G., \& Verhaeghe, P. (2005). Wechsler intelligence scale for children - third edition (Dutch version). Amsterdam: NIP.

Piazza, M., Izard, V., Pinel, P., Le Bihan, D., \& Dehaene, S. (2004). Tuning curves for approximate numerosity in the human intraparietal sulcus. Neuron, 44, 547-555. doi: 10.1016/j.neuron.2004.10.014

Ramani, G. B., \& Siegler, R. S. (2008). Promoting broad and stable improvements in lowincome children's numerical knowledge through playing number board games. Child Development, 79, 375-394. doi: 10.1111/j.1467-8624.2007.01131.x

Ramani, G. B., \& Siegler, R. S. (2011). Reducing the gap in numerical knowledge between low- and middle-income preschoolers. Journal of Applied Developmental Psychology, 32, 146-159. doi: 10.1016/j.appdev.2011.02.005

Ramani, G. B., Siegler, R. S., \& Hitti, A. (2012). Taking it to the classroom: number board games as a small group learning activity. Journal of Educational Psychology, 104, 661-672. doi: 10.1037/a0028995

Räsänen, P., Salminen, J., Wilson, A. J., Aunio, P., \& Dehaene, S. (2009). Computer-assisted intervention for children with low numeracy skills. Cognitive Development, 24, 450472. doi: 10.1016/j.cogdev.2009.09.003

Reigosa-Crespo, V., Valdés-Sosa, M., Butterworth, B., Estévez, N., Rodríguez, M., Santos, E., Torres, P., Suárez, R., \& Lage, A. (2012). Basic numerical capacities and prevalence of developmental dyscalculia: The Havana survey. Developmental Psychology, 48, 123-135. doi: 10.1037/a0025356

Schalock, R. L., Borthwick-Duffy, S. A., Bradley, V. J., Buntinx, W. H. E., Coulter, D. L., Craig, E. M., ... Yeager, M. H. (2010). Intellectual disability: Definition, 
classification, and systems of supports (11th ed.). Washington, DC: American Association on Intellectual and Developmental Disabilities.

Schneider, W., Eschmann, A., \& Zuccolotto, A. (2002). E-prime reference guide. Pittsburg, PA: Psychology Software Tools.

Sekuler, R., \& Mierkiewicz, D. (1977). Children’s judgments of numerical inequality. Child Development, 48, 630-633. doi: 10.2307/1128664

Siegler, R. S., \& Ramani, G. B. (2008). Playing linear numerical board games promotes lowincome children’s numerical development. Developmental Science, 11:5, 655-661. doi: 10.1111/j.1467-7687.2008.00714.x

Siegler, R. S., \& Ramani, G. B. (2009). Playing linear number board games - but not circular ones - improves low-income preschoolers' numerical understanding. Journal of Educational Psychology, 101, 545-560. doi: 10.1037/a0014239

Tellegen, P. J., Winkel, M., Wijnberg-Williams, B. J., \& Laros, J. (1998). Snijders-Oomen nonverbal intelligence test, SON-R 2.5-7. Manual \& research report. Lisse: Swets and Zeitlinger.

Vander Steene, G., \& Bos, A. (1997). Wechsler preschool and primary scale of intelligence revised, Flemish-Dutch version. Lisse: Swets \& Zeitlinger.

Van Nes, F., \& Doorman, N. (2011). Fostering young children’s spatial structuring ability. International Electronic Journal of Mathematics Education, 6, 27-39.

Whyte, J. C., \& Bull, R. (2008). Number games, magnitude representation, and basic number skills in preschoolers. Developmental Psychology, 44, 588-596. doi: 10.1037/00121649.44.2.588

Wilson, A. J., Dehaene, S., Dubois, O., \& Fayol, M. (2009). Effects of an adaptive game intervention on accessing number sense in low-socioeconomic-status kindergarten children. Mind, Brain, and Education, 3, 224-234. doi: 10.1111/j.1751- 
228X.2009.01075.x

Wilson, A. J., Dehaene, S., Pinel, P., Revkin, S. K., Cohen, L., \& Cohen, D. (2006a). Principles underlying the designs of “The Number Race”, an adaptive computer game for remediation of dyscalculia. Behavioral and Brain Functions, 2(19). doi:10.1186/1744-9081-2-19

Wilson, A. J., Revkin, S. K., Cohen, D., Cohen, L., \& Dehaene, S. (2006b). An open trial assessment of "The Number Race”, an adaptive computer game for remediation of dyscalculia. Behavioral and Brain Functions, 2(20). doi:10.1186/1744-9081-2-20

World Health Organization (1993). The ICD-10 classification of mental and behavioural disorders: diagnostic criteria for research. Geneva, Switzerland: World Health Organization. 
Table 1

Mean accuracy and reaction times for both groups at pretest and posttest

\begin{tabular}{llcccc}
\hline & & \multicolumn{2}{c}{ Pretest } & \multicolumn{2}{c}{ Posttest } \\
\cline { 3 - 6 } & & $M$ & $S D$ & $M$ & $S D$ \\
\hline Motor reaction time (ms) & Color & 627.11 & 143.39 & 614.49 & 125.35 \\
& Numerical & 637.37 & 230.47 & 605.78 & 154.02 \\
Symbolic comparison & & & & & \\
Accuracy & Color & 0.81 & 0.11 & 0.85 & 0.09 \\
& Numerical & 0.83 & 0.09 & 0.83 & 0.09 \\
Reaction time (ms) & Color & 1045.82 & 281.63 & 1157.37 & 252.23 \\
& Numerical & 1224.93 & 392.53 & 1104.49 & 317.22
\end{tabular}

Non-symbolic comparison

\begin{tabular}{|c|c|c|c|c|c|}
\hline \multirow[t]{2}{*}{ Accuracy } & Color & 0.82 & 0.14 & 0.87 & 0.08 \\
\hline & Numerical & 0.87 & 0.07 & 0.89 & 0.07 \\
\hline \multirow[t]{2}{*}{ Reaction time (ms) } & Color & 936.34 & 314.72 & 791.00 & 162.74 \\
\hline & Numerical & 901.72 & 228.10 & 808.59 & 165.37 \\
\hline \multirow[t]{2}{*}{ Tempo Test Arithmetic ${ }^{\mathrm{a}}$} & Color & 6.87 & 3.11 & 7.40 & 4.15 \\
\hline & Numerical & 5.20 & 3.26 & 6.93 & 3.69 \\
\hline
\end{tabular}


Figure 1. Example of the numerical domino game (top) and the control color domino game (bottom).
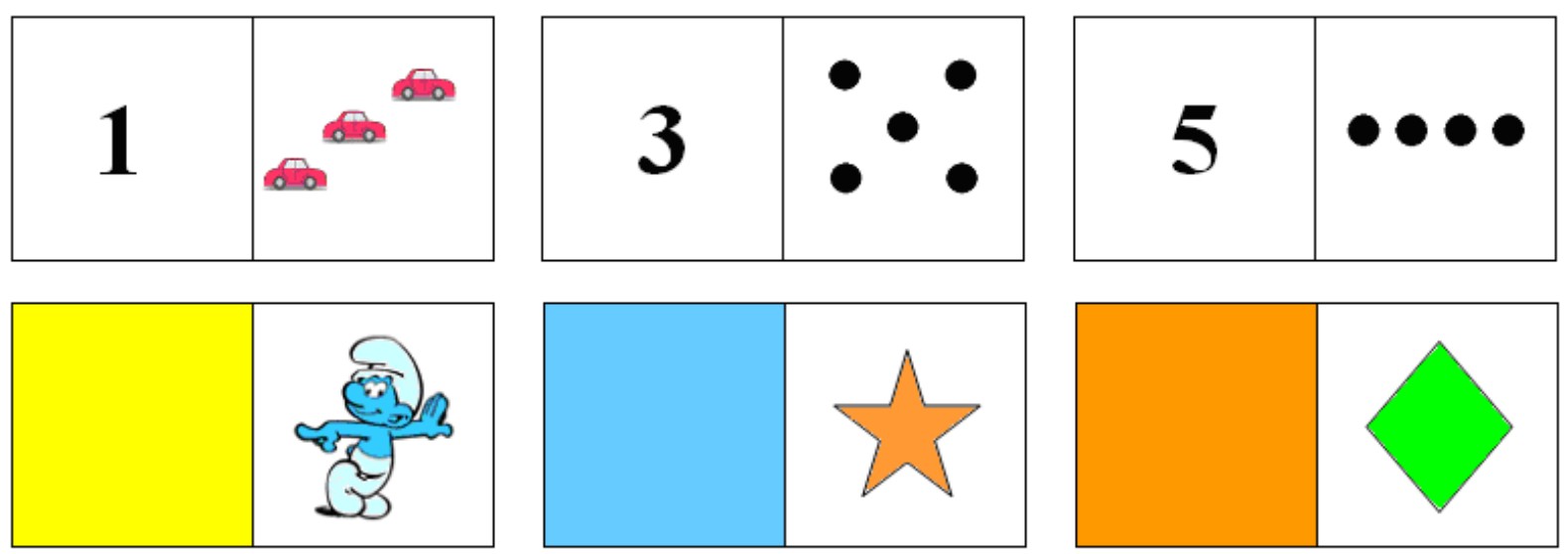
Figure 2. Interaction between group and session on the symbolic numerical comparison task (reaction time).

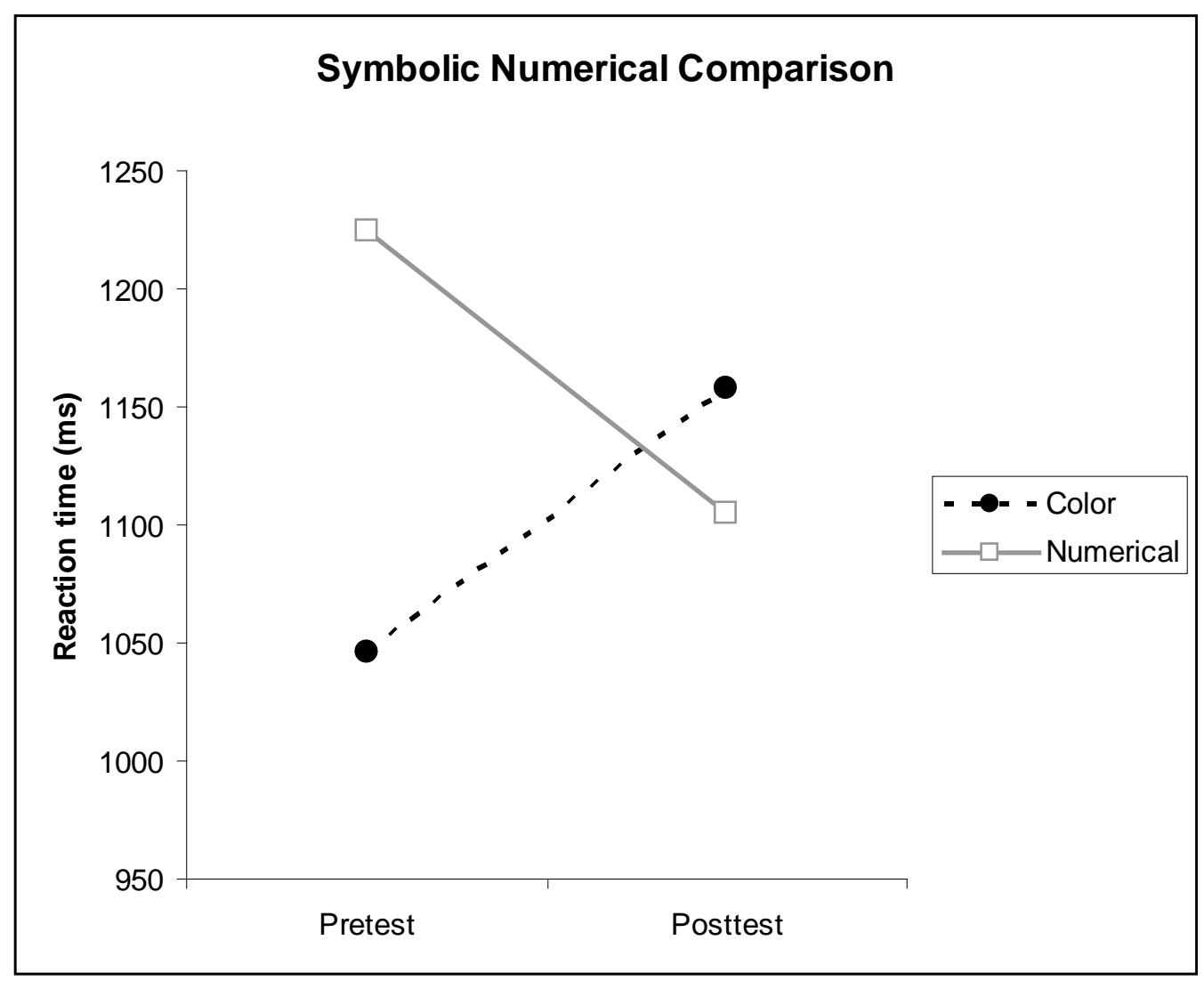




\section{Appendix}

Intervention sessions for the numerical domino game

\begin{tabular}{|c|c|c|c|}
\hline Session & Quantities & Course of the sessions & Tiles \\
\hline 1 & $1-5$ & $\begin{array}{l}\text { Game 1: matching numbers to dot arrays (working from left to right) } \\
\text { Game 2: matching dot arrays to numbers (working from left to right) }\end{array}$ & $\begin{array}{l}\text { left: numbers/right: dot arrays } \\
\text { left: dot arrays/ right: numbers }\end{array}$ \\
\hline 2 & $1-5$ & $\begin{array}{l}\text { Game 1: matching numbers to dot arrays + vice versa (both directions) } \\
\text { Game 2: matching numbers to object arrays + vice versa (working in both } \\
\text { directions) }\end{array}$ & $\begin{array}{l}\text { left: numbers/right: dot arrays } \\
\text { left: numbers/right: object arrays }\end{array}$ \\
\hline 3 & $1-5$ & $\begin{array}{l}\text { Game 1: matching numbers to dot and object arrays + vice versa (working in } \\
\text { both directions) } \\
\text { Game 2: identical to game 1, with a time-limit }\end{array}$ & $\begin{array}{l}\text { left: numbers/right: dot and object } \\
\text { arrays } \\
\text { left: numbers/right: dot and object } \\
\text { arrays }\end{array}$ \\
\hline 4 & $6-10$ & $\begin{array}{l}\text { Game 1: matching numbers to dot arrays (working from left to right) } \\
\text { Game 2: matching dot arrays to numbers (working from left to right) }\end{array}$ & $\begin{array}{l}\text { left: numbers/right: dot arrays } \\
\text { left: dot arrays/ right: numbers }\end{array}$ \\
\hline 5 & $6-10$ & $\begin{array}{l}\text { Game 1: matching numbers to dot arrays + vice versa (working in both } \\
\text { directions) } \\
\text { Game 2: matching numbers to object arrays + vice versa (working in both } \\
\text { directions) }\end{array}$ & $\begin{array}{l}\text { left: numbers/right: dot arrays } \\
\text { left: numbers/right: object arrays }\end{array}$ \\
\hline 6 & $6-10$ & $\begin{array}{l}\text { Game 1: matching numbers to dot and object arrays + vice versa (working in } \\
\text { both directions) } \\
\text { Game 2: identical to game 1, with a time-limit }\end{array}$ & $\begin{array}{l}\text { left: numbers/right: dot and object } \\
\text { arrays } \\
\text { left: numbers/right: dot and object } \\
\text { arrays }\end{array}$ \\
\hline 7 & $1-10$ & $\begin{array}{l}\text { Game 1: matching numbers to dot arrays (working from left to right) } \\
\text { Game 2: matching dot arrays to numbers (working from left to right) }\end{array}$ & $\begin{array}{l}\text { left: numbers/right: dot arrays } \\
\text { left: dot arrays/ right: numbers }\end{array}$ \\
\hline 8 & $1-10$ & $\begin{array}{l}\text { Game 1: matching numbers to dot arrays + vice versa (working in both } \\
\text { directions) } \\
\text { Game 2: identical to game 1, with a time-limit }\end{array}$ & $\begin{array}{l}\text { left: numbers/right: dot arrays } \\
\text { left: numbers/right: dot arrays }\end{array}$ \\
\hline
\end{tabular}




\begin{tabular}{|c|c|c|c|}
\hline Session & Colors & Course of the sessions & Tiles \\
\hline 1 & $\begin{array}{l}\mathrm{Y}, \mathrm{P}, \mathrm{Bl} \\
\mathrm{Br}, \mathrm{W}\end{array}$ & $\begin{array}{l}\text { game 1: matching colors to colored shapes (working from left to right } \\
\text { game 2: matching colored shapes to colors (working from left to right }\end{array}$ & $\begin{array}{l}\text { left: colors/right: colored shapes } \\
\text { left: colored shapes/right: colors }\end{array}$ \\
\hline 2 & $\begin{array}{l}\mathrm{Y}, \mathrm{P}, \mathrm{Bl} \\
\mathrm{Br}, \mathrm{W}\end{array}$ & $\begin{array}{l}\text { game 1: matching colors to colored shapes + vice versa (both directions) } \\
\text { game 2: matching colors to colored cartoons + vice versa (both directions) }\end{array}$ & $\begin{array}{l}\text { left: colors/right: colored shapes } \\
\text { left: colores/right: colored cartoons }\end{array}$ \\
\hline 3 & $\begin{array}{l}\mathrm{Y}, \mathrm{P}, \mathrm{Bl} \\
\mathrm{Br}, \mathrm{W}\end{array}$ & $\begin{array}{l}\text { game 1: matching colors to colored shapes and cartoons }+ \text { vice versa (both } \\
\text { directions) } \\
\text { game 2: identical to game } 1 \text {, with a time-limit }\end{array}$ & $\begin{array}{l}\text { left: colors/right: colored shapes and } \\
\text { cartoons } \\
\text { left: colors/right: colored shapes and } \\
\text { cartoons }\end{array}$ \\
\hline 4 & $\begin{array}{l}\mathrm{O}, \mathrm{G}, \mathrm{R} \\
\mathrm{Gr}, \mathrm{Pu}\end{array}$ & $\begin{array}{l}\text { game 1: matching colors to colored shapes (working from left to right } \\
\text { game 2: matching colored shapes to colors (working from left to right }\end{array}$ & $\begin{array}{l}\text { left: colors/right: colored shapes } \\
\text { left: colored shapes/ right: colors }\end{array}$ \\
\hline 5 & $\begin{array}{l}\mathrm{O}, \mathrm{G}, \mathrm{R} \\
\mathrm{Gr}, \mathrm{Pu}\end{array}$ & $\begin{array}{l}\text { game 1: matching colors to colored shapes + vice versa (both directions) } \\
\text { game 2: matching colors to colored cartoons + vice versa (both directions) }\end{array}$ & $\begin{array}{l}\text { left: colors/right: colored shapes } \\
\text { left: colores/right: colored cartoons }\end{array}$ \\
\hline 6 & $\begin{array}{l}\mathrm{O}, \mathrm{G}, \mathrm{R} \\
\mathrm{Gr}, \mathrm{Pu}\end{array}$ & $\begin{array}{l}\text { game 1: matching colors to colored shapes and cartoons }+ \text { vice versa (both } \\
\text { directions) } \\
\text { game 2: identical to game } 1 \text {, with a time-limit }\end{array}$ & $\begin{array}{l}\text { left: colors/right: colored shapes and } \\
\text { cartoons } \\
\text { left: colors/right: colored shapes and } \\
\text { cartoons }\end{array}$ \\
\hline 7 & All colors & $\begin{array}{l}\text { game 1: matching colors to colored shapes (working from left to right) } \\
\text { game 2: matching colored shapes to colors (working from left to right) }\end{array}$ & $\begin{array}{l}\text { left: colors/right: colored shapes } \\
\text { left: colored shapes/right: colors }\end{array}$ \\
\hline 8 & All colors & $\begin{array}{l}\text { game 1: matching colors to colored shapes }+ \text { vice versa (both directions) } \\
\text { game 2: identical to game } 1 \text {, with a time-limit }\end{array}$ & $\begin{array}{l}\text { left: colors/right: colored shapes } \\
\text { left: colored shapes/right: colors }\end{array}$ \\
\hline
\end{tabular}

